\title{
Ódio como potência disruptiva e instauradora de comunicação
}

\author{
Fagner Torres de França' \\ http://orcid.org/0000-0003-2170-4288 \\ Lilian Carla Muneiro' \\ https://orcid.org/0000-0002-2226-7297 \\ I - UFRN \\ Natal (RN), Brasil.
}

KIFFER, A.; GIORGl, G. Ódio político e

políticas do ódio: lutas gestos e escritas do

presente. Rio de Janeiro, Bazar do tempo, 2019. 136 p. (Coleção Porque Política?, v. 5).

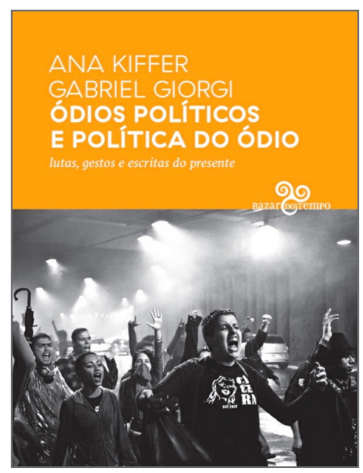

Resumo: A recente obra de Ana Kiffer e Gabriel G’iorgi, Ódios políticos e política do ódio: lutas, gestos e escritas do presente (2019), é fundamental para o avanço na compreensão de um nebuloso fenômeno do presente: o ódio como um dos principais afetos mobilizadores da política em tempos atuais. Como surge, ao que responde e qual sua potência comunicativa são algumas das questões suscitadas pelos autores no livro. A novidade apresentada está justamente em investigar o ódio não apenas como restaurador, mas como instaurador de novas demandas, imaginações, visibilidades e apostas coletivas.

Palavras-chave: ódio; política; comunicação; democracia.

Abstract. Hate as a disruptive and communicative power - The recent work of Ana Kiffer and Gabriel Giorgi, Political hatred and hate politics: struggles, gestures and writings of the present (2019), is fundamental for the advancement in understanding a nebulous phenomenon of the present: hatred as one of the main mobilizing effects of politics today. How it arises, what it responds to and what its communicative power is are some of the questions raised by the authors in the book. The novelty presented is precisely to inquire into hatred not only as a restorer but as an instigator of new demands, imaginations, visibilities, and collective bets.

Keywords: hate; politics; communication; democracy.

A recente obra de Ana Kiffer, escritora, pesquisadora e professora do Programa de Pós-Graduação em Literatura, Cultura e Contemporaneidade da PUC-Rio, e Gabriel 
Giorgi, crítico, pesquisador e professor da New York University, apresenta a dimensão complexa do ódio. Enquanto Homo sapiens-demens, como sugere o pensador francês Edgar Morin (2015), somos seres constituídos pela ambivalência do ódio e do amor, da razão e da emoção, forças indissociáveis de disjunção e conjunção. Freud aponta essa dupla constituição do ser em algumas de suas obras (1996; 2010).

Seguindo linha semelhante, Kiffer e Giorgi (2019) recuperam a impossibilidade de pensar um sujeito político dotado apenas de razão, negando a dimensão de seus regimes de afecções. Ou seja, o ódio como "condensador e modulador de afetos diversos, que conjuga uma constelação de paixões que passa pela reprimenda, pela fúria, pela ira e pela indignação" (p. 12). Um ódio que se inscreve (mais do que se escreve) nos gestos, corpos, gritos, palavras de ordem, reivindicações, lutas por reconhecimento.

O livro da dupla Kiffer-Giorgi é composto de três partes, sendo uma apresentação e dois ensaios: O ódio e os desafios da relação: escritas dos corpos e afecções políticas, de autoria de Ana Kiffer, e Arqueologia do ódio: apontamentos sobre escrita e democracia, por Gabriel Giorgi. Kiffer divide basicamente sua exposição em três cenas. A Cena 1: compulsão, baseia-se em uma gestualidade do corpo; a Cena 2: corpos de bordas, bordas dos corpos, analisa a entrada dos corpos precários em uma nova cena pública em formação; e a Cena 3: Relação, coloca em proeminência o conceito de Relação, trabalhado a partir de Édouard Glissant.

A Cena 1: compulsão, baseia-se em uma gestualidade do corpo que se repete como um eterno retorno das diferenças em jogo, como a ideia do punho erguido e cerrado em sinal de protesto como operador de subjetivação política, simbologia da insubmissão e da revolta. O enigma da revolta, como colocado por Foucault (2019), jaz no fato de que as afecções políticas são sempre um conjunto de desejos, emoções e recalques insuficientemente formulados. Por isso, é também um espaço de subjetivação política sempre em disputa. O gesto do polegar e o indicador formando um " $\mathrm{L}$ ", de repente, por um simples deslocamento posicional, transforma-se em uma arma. Instaura-se aí um novo subjetivador político. Nas palavras de Kiffer, "Um gesto $\rightarrow$ um espelhamento caótico $\rightarrow$ Um desejo livre de objeto -> Um só gesto" (KIFFER; GIORGI, 2019, p. 37), assumindo uma demarcação ainda mais profunda de desligamento político.

Sendo a política uma ontologia pluralista por definição, como defendido por Hannah Arendt (2002), o gesto em arma propõe a inviabilidade de reconhecimento político da diferença. Aqui entra em campo a Cena 2: corpos de bordas, bordas dos corpos, corpos das margens, corpos precários. Quando estes corpos, até então apagados, iluminam novas possibilidades de organização política (tendo em vista não apenas os acontecimentos referentes às Jornadas de Junho, mas os movimentos antissistêmicos surgidos desde pelo menos a Primavera Árabe) e entram no proscênio, convocam modos outros de subjetivação política justamente pela força inventiva e disruptiva do ódio instaurador (diferente do conservador, do reacionário), capaz de deslocar antigas crenças, narrativas e performances 
fortemente estabelecidas. Por isso, a autora fala de uma "inscrição do ódio como afecção política construtiva, mesmo que momentaneamente desorganizadora" (KIFFER; GIORGI, 2019, p. 43), aparentemente caótica.

A importância de se ater aos gestos, corpos e forças de subjetivação ancora-se no fato de que, para Kiffer, não é possível haver reforma política sem reforma discursiva. Isso implica uma partilha do sensível (RANCIÈRE, 2005), uma luta por reconhecimento, pois trata-se de uma verdadeira guerra discursiva enquanto guerra de territórios, e o ódio é uma força apropriada e apropriadora desses discursos. Portanto, a importância de pensá-lo como subjetivador político. Trata-se do ódio como afeto interruptivo, disruptivo e instaurador de novas dinâmicas sociais. Nesse sentido, a Cena 3: Relação, coloca em proeminência o conceito de Relação, trabalhado a partir de Édouard Glissant.

Aqui, cabe acentuar a diferença entre as noções de desligamento e separação. As forças do capital, assim como o ódio restaurador, atuam como força de negação e desligamento. Seja pelo consumo, seja pela eliminação do pensamento político divergente. O desligamento atua fundamentalmente por meio da escrita hegemônica referendada nos livros, jornais, imprensa, nas imposições do mercado financeiro, na reafirmação dos já conhecidos lugares de fala, nos privilégios eternamente reproduzidos. As forças de separação, diferentemente, atuam pelas bordas, pelas escritas precárias, pelos gritos informes, manifestações, redes sociais digitais, panfletos, gestos, corpos marginais, ou seja, nas arenas microfísicas do poder.

Dessa forma, a separação pela resistência pretende instituir os lugares de reconhecimento a partir dos quais é possível entrar em relação com o outro (e não sua negação) e estabelecer suas próprias agendas. É nesse sentido que a arte também opera fortemente. No dizer de Kiffer, os "sistemas vivos de inscrição - artísticos, literários, arquivísticos, orais, corporais, entre outros, estão hoje no cerne da proposição e do fomento de novas imaginações políticas (KIFFER; GIORGI, 2019, p. 67), vide os ataques a exposições de arte pelas tropas moralistas do ódio ressentido.

O segundo ensaio, elaborado por Gabriel Giorgi, argentino de nascença, conhecedor dos horrores da ditadura em seu país (1966-73), que deixou cerca de 30 mil mortos e desaparecidos, intitula-se Arqueologia do ódio: apontamentos sobre escrita e democracia. Revela os desdobramentos do ódio na Argentina desde pelo menos os governos Cristina Kirchner (2008-15), durante os quais a polarização política alçou ao debate político à época a palavra "crispação", demarcando, para o autor, algo fundamental: "o rompimento das retóricas do consenso democrático que haviam marcado a norma de uma democratização" (KIFFER; GIORGI, 2019, p. 80).

Giorgi percebe, assim como Kiffer, o laboratório de linguagens, gestos e inscrições que começam a surgir tanto lá como cá a partir da retórica do ódio, pois uma "crispação" envolve não apenas palavras e gritos, mas emoções, músculos e nervos. Daí os autores afirmarem não haver como entender o presente sem se debruçar sobre este fenômeno. 
Em outras palavras, o ódio é capaz de traçar linhas de fuga que podem ou não abrir novos espaços de desterritorialização, embora essas linhas possam endurecer-se fortemente. Mas, o essencial, no momento, é abrir a disputa do campo narrativo.

Giorgi trabalha com o que chama de Materiais, três instalações artísticas, no Brasil e na Argentina, alinhadas com a discussão em tela. A primeira chama-se Diário do Ódio, de Roberto Jacoby e Sid Krocmalny, de 2014, uma colagem de discursos de ódio retirados do WhatsApp e Facebook de pessoas de ambos os países. Uma delas diz: "Sejamos sensatos, tem que matar, senão não resolve. Essa é a nova cara do Brasil...".

A segunda instalação chama-se Odiolândia, de 2017, da artista brasileira Giselle Beiguelman. A obra projeta, em loop, frases extraídas de fóruns online apoiando a invasão da Polícia Militar de São Paulo à região conhecida como Cracolândia, onde vivem e sobrevivem os corpos das margens, os corpos matáveis, as vidas nuas e precárias, invisíveis. Menos um é o nome da terceira instalação, apresentada por Verônica Stigger no ano de 2014, em Sorocaba, na qual são extraídas da internet e expostas ao público imagens de indígenas assassinados no Brasil, seguidas dos comentários comemorativos dos internautas brasileiros. Na interpretação de Giorgi,

\begin{abstract}
Essas instalações têm a inteligência e o poder de enfocarem a centralidade do ódio como afeto político nas democracias contemporâneas, sinalizando a inédita estridência com que se exibe e reclama um lugar no repertório das enunciações. O ódio como tonalidade prevalente em democracias que parecem sacudir as retóricas (ao menos declaradas) de consenso, diálogo e direitos humanos que haviam marcado as transições pós-ditatoriais - um ódio, portanto, como marcador de outra modulação e outro tom democrático (KIFFER; GIORGI, 2019, p. 89).
\end{abstract}

Os pactos civilizatórios são, portanto, colocados em suspeição. Pelo menos para alguns corpos de borda. Para eles, a exceção sempre existiu. Mas o ódio instaurador pode ser visto, aqui, como disputas de enunciação pelos limites do dizível em uma democracia, uma guerra pela dicção democrática. Entram aqui as vozes e lutas feministas, antirracistas e anticapitalistas, por exemplo, no sentido de expandir os limites de enunciação e reconhecimento de direitos sempre negados. As modulações do ódio colocam em jogo a palavra na democracia, redistribuindo vozes, sentidos, afecções, visibilidades e sensibilidades.

No tópico Arquivos do ódio, Giorgi interpreta as instalações na interseção entre afetos políticos e tecnologias da escrita, gerando o que ele chama de "escritas do ódio" e seu novo léxico ("Cancelar", "Lacrar", "Vomitaço" etc.), capazes de elaborar também reconfigurações subjetivas além de um rearranjo na própria ideia de esfera pública, entre o que pode ou não ser dito, por quem, quais as agendas em discussão.

Tudo se passa a partir de um Barulho público, nome do tópico seguinte. Um barulho capaz de reorganizar o campo do dizível. Trata-se de uma cacofonia de vozes, do malentendido que opera no limite da linguagem articulada, entre gritos e sussurros, o online e 
o offline, o indizível e o dizível ainda em formação. Diz ele: "A fricção entre voz e palavra: em que não se sabe se há significados válidos, capazes de definir imagens e sentidos do coletivo. Aí se situa o ódio" (KIFFER; GIORGI, 2019, p. 95, grifo do autor).

O livro finaliza com outros quatro pequenos tópicos (Guerras de subjetividade, Escritas performáticas, Pedagogias Públicas e Práticas de Publicação) que, sumariados, retomam e ao mesmo tempo arrematam o diálogo desenvolvido nos dois ensaios. As emanações modernas do ódio repousam em distinções biopolíticas sobre o que seria ou não humano, ou seja, o corpo sem qualidades passível de eliminação física e simbólica (negro, mulher, pobre, nordestino etc.). Nesse sentido, as linguagens do ódio podem significar uma outra organização do social a partir da língua, dos gestos, da visibilidade e do reconhecimento, na medida em que produz o deslocamento de uma certa ideia de democracia e esfera pública, constituindo uma nova forma de aposta coletiva. Como aponta Giorgi, o "ódio político é, fundamentalmente, circulação: quer contagiar, é adesivo; busca demarcar um coletivo a partir de um ódio comum" (KIFFER; GIORGI, 2019, p. 108, grifo do autor).

Ódio políticos e política do ódio: lutas, gestos e escritas do presente (KIFFER; GIORGI, 2019), é um livro indispensável para alunos e professores, cientistas políticos, sociólogos, antropólogos e comunicólogos ou qualquer pessoa que queira compreender algumas questões centrais das disputas políticas do presente de forma mais ampla, rizomática e transversal, no nível da linguagem, do discurso, da imaginação, da comunicação, das inscrições do ódio em corpos, gestos e afetos.

Fagner Torres de França é jornalista e doutor em Ciências Sociais pela UFRN.

fagnertf@yahoo.com.br

Lilian Carla Muneiro é professora do Departamento de Comunicação Social da UFRN e doutora em Comunicação e Semiótica (PUC/SP).

lilianmuneiro@gmail.com

\section{Referências}

ARENDT, H. O que é política? Rio de Janeiro: Bertrand Brasil, 2002.

FOUCAULT, M. O enigma da revolta. São Paulo: $n$ - 1 Edições. 2019.

FREUD, S. Totem e Tabu (1913). In: Edição Standard Brasileira das Obras Psicológicas Completas de Sigmund Freud, Vol. XIII. Rio de Janeiro: Imago, 1996. 
O mal-estar na civilização, novas conferências introdutórias à psicanálise e outros textos (1930-1936). São Paulo: Companhia das Letras, 2010.

KIFFER, A; GIORGI, G. Ódio político e políticas do ódio: lutas gestos e escritas do presente. Rio de Janeiro: Bazar do tempo, 2019.

MORIN, E. Introdução ao pensamento complexo. Porto Alegre : Sulina, 2015.

RANCIÈRE, J. A partilha do sensível: estética e política. São Paulo: Editora 34, 2005.

Resenha recebida em 15/04/2020

e aprovada em 30/04/2020. 